\title{
Depression, Anxiety at School and Self-Esteem in Children with Learning Disabilities
}

\section{Marianna Alesi ${ }^{\star}$, Gaetano Rappo and Annamaria Pepi}

Department of Psychological Sciences, Pedagogy and Education, University of Palermo, Viale Sciences Building 15, 90135, Palermo, Italy

*Corresponding author: Dr. Marianna Alesi, Department of Psychological Sciences, Pedagogy and Education, University of Palermo, Viale Sciences Building 15, 90135, Palermo, Italy, Tel: +09123897702; Fax: +0916513825; E-mail: marianna.alesi@unipa.it

Received: June 03, 2014; Accepted: July 09, 2014; Published: July 20, 2014

Copyright: (c) 2014 Alesi M et al. This is an open-access article distributed under the terms of the Creative Commons Attribution License, which permits unrestricted use, distribution, and reproduction in any medium, provided the original author and source are credited.

\begin{abstract}
Educational research places emphasis on the fact that pupils with Learning Disabilities may develop depressive and anxiety symptoms characterized by lower levels of self-esteem.

The aim of this research is to compare the levels of depression, anxiety at school and self-esteem in children with learning disabilities, mathematical disabilities and a control group who showed typical learning. The participants were 132 children (52 girls and 80 boys), with an average age of 9 years, attending the fourth grade of primary school. These pupils were selected by scores on a battery of tests commonly used in Italy for the assessment of learning disabilities. On the whole, analyses revealed that children with Learning Disabilities and Mathematical Disabilities showed higher level of depression and school anxiety as well as lower rated self-esteem at school than children with typical learning. Moreover our findings highlight the co-occurrence of depressive and anxiety symptoms in pupils with Learning Disabilities.
\end{abstract}

One of the issues that emerges from this study is the need to implement prevention programs aimed at identifying at an early age high-risk children showing increased levels of depression and anxiety. Moreover, these findings highlight the importance to find which are the most appropriate educational and clinical interventions to reduce cognitive maladaptive strategies in school aged children.

Keywords: Depression; School anxiety; Self-esteem; Learning disabilities; Childhood

\section{Introduction}

Recent developments in the field of mental health have led to an increasing interest in the early identification of anxiety and depression symptoms in school-aged population. Longitudinal and epidemiological studies are at the heart of this interest; the first ones documented how depressive symptoms increase in a linear way by creating a continuity from the early depressive episodes to the major depression in adults [1]. Similarly, in the long term, anxious children and adolescents showed an increased risk for enlarged rates of unemployment, welfare assistance, lost productivity, use of medical services, all resulting in extremely high economic health costs [2,3].

Second, epidemiological studies reveal rates of anxiety disorders in pre-school age children and adolescents ranging between $2.1 \%$ and $25 \%$ depending on methodological differences in the assessment plans [4-6]. About the $75 \%$ of all anxiety disorders starts at a median age between 11 and 21 years $[7,8]$.

It is worth noting the elevated co-occurrence between the abovementioned mental complaints. So far, anxiety disorders are frequently associated to depressive symptoms with rates ranging from 16 to $50 \%$ increasing in chronicity and severity [9]. A common core of high negative affects is the leading cause this comorbidity. The consequence is the interference with daily functioning for a sizeable population of children [10].
In spite of this occurrence, childhood mental disorders such as depression and anxiety are undertreated and often misinterpreted. Most studies have only been carried out on adult samples and only recently the focus has been moved to children and adolescents [11,12].

\section{Depression in Children}

Although scarce literature has been produced on this issue, studies carried out on children samples have identified biomarkers similar to those observed in adults depression [6]. These concern the altered functioning at level of neuroendocrine and metabolic systems as well as enhanced inflammatory markers and decreased neurotropic factors. The most typical symptoms, therefore, include: sleep and eating complaints, lack of energy and interest in activities previously enjoying, problems in concentrating, pessimism, hopeless, sadness, irritability, low self-esteem, suicidal thinking. Moreover, preschool depression is characterized by motor problems including poor gross motor and coordinative skills $[13,14,15]$

The nature of above-mentioned symptoms confirms the multidimensional etiology of children depression. It's widely accepted how complex interactions between genetic and environmental factors affect the onset and the maintenance of depressive symptoms $[6,16,17]$. Nevertheless, this symptomatology would differently manifest depending on the gender and the age. Specifically, girls appear to be more likely to manifest depressive symptoms than boys; in turn, gender differences increase by age thorough adolescence when the occurrence of depressive symptoms is rated to be twice that of males [18]. These gender differences are influenced by factors of psychosocial risk such as lower levels of school self-esteem and self- 
efficacy [19]. To date, ample evidence has been found associating selfreported depressive symptoms with school under-achievement [20-23]. In their review, Cuijpers, Van Straten, Smits and Smit analyzed in deep this issue and identified direct and mediated links between the level of mood and the school outcomes [24]. First, typical symptoms such as cognitive biases, lack of interest and loss of energy negatively affect performance at school [25]. More specifically, cognitive biases effect on functioning of executive control and cause inadequate inhibition processes and scarce concentration, as well as dysfunctional updating in working memory and forgetting [26]. Second, the relationship between depressive symptoms and school achievement is mediated by variables such as a maladaptive motivational profile including lower self-esteem [27], lower perceived academic competence and entity personal conceptions of intelligence [28].

In this field, Steca et al. [17], highlighted the role of self-esteem; when pupils face a challenging or threatening task aimed at evaluating their competences, a low self-worth may affect their mood. However, a low self-worth can obstacle social relationships with classmates by encouraging feelings of isolation and depressed behaviors. So, [29] argued the Reciprocal Effects Model (REM) in which self-worth both affects and is affected by school achievement, each leading to gains or loss in the other. Adequate levels of self-esteem promote and encourage the capacity to cope with academic tasks by employing effective study methods and actively participating in the learning process [30]. On the other hand, a variety of studies documented the close association between poor school achievement or learning disabilities and lower levels of school self-esteem and academic selfconcept. Whilst, high achievers are more likely to develop positive school emotions and affects, which, in turn, tend to increase their engagement and motivation in school activities and tasks [31].

To summarize, students with school under-achievement are more likely to show lower global self-esteem and to report increasing anxious and depressive symptomatology than typical achievers [32-34].

To our knowledge, the literature is lacking on the exam of anxiety and depression in learning disabilities, which are considered debilitating conditions for pupils. Learning to read and to calculate are central activities undertaken by children during the first years of school and are considered traditional criteria of success. Not surprisingly, low or bad achievement in these two domains can enable pupils to develop secondary problems in the self-perception and emotional domain. At long term these pupils can perceive themselves as failures and develop depressive episodes. In this context, poor reading and mathematical difficulties increase children's use of selfprotective strategies to reduce the psychological stress associated with possible failure. Due to fear of failure, children often deliberately tend to avoid challenging situations by decreasing effort and using selfhandicapping behaviors aimed at protecting their self-worth [35]. In turn, all these maladaptive conditions hamper subsequent improvement in reading and mathematics by creating a vicious circle characterized by mutually increasing in duration and severity $[36,37]$.

\section{Anxiety in Children}

A variety of authors recognized anxiety disorders as the most prevalent child mental impairments [38].

Anxiety appears to be a multidimensional construct composed by physiological, cognitive, affective and behavioral components. There is high agreement among scholars and practitioners that typical fears clearly characterize developmental patterns. In other words, it's a typical reaction to stress, an unpleasant emotional response evocated by imagined or real threat and danger. Only when the level of anxiety becomes excessive and creates interferences with daily functioning, it evolves into anxiety disorder both in adults and in children [39-41].

Childhood and adolescence are identified as the main risk developmental phases for the beginning of anxiety disorders [42]. Consequently, there is an increasing emphasis on the analysis of subthreshold anxiety characterized by subclinical symptoms of anxiety in children and adolescents $[43,44]$. Fears concerning separation anxiety decrease during first childhood whereas fears about school and school anxiety increase during medium childhood because of the central role of learning activities during school age [45,46]. School anxiety describes a discomfort reaction associated with unpleasant emotions and a state of distress occurring in response to situations involving school learning tasks that are perceived as threatening to self-worth. A variety of studies documented the antecedents and the reinforcing factors of school anxiety and subdivided it into three main categories: environmental, personal and cognitive causes. The first ones embrace negative experiences in class or with classmates or with teachers. Personal causes concern the maladaptive motivational profile and include a maladaptive student self-image, a lower level of self-esteem, a lack of confidence as well as individual characteristics such as the big five personality traits [47]. Finally, cognitive causes include a lower level of abstract or logical thinking, poor cognitive abilities or inadequate learning styles [48-50]. These factors are traditionally assumed to play a pivotal role in the behavior responses of anxious pupils [51]. That is, when faced with some perceived or real threats, novel or ambiguous events, anxious students tend to make cognitive errors or distortions characterized by a negative bias in the interpretation of facts. More specifically, they process not all real information but they address their attention to the information relevant to the threat [52].

The fear of failure at school is very common at this age. Anyway when levels of anxiety become abnormal, these can have negative effects on cognitive functioning and, at long term, on school performance and outcomes. The immediate consequence is the introduction of task-irrelevant thoughts which interfere with the information processing system by creating distracting information able to move the attentional focus and reduce space in working memory. High levels of anxiety during reading or calculation interfere with the phonological loop and cause the need for articulatory rehearsal resulting in decreased working memory capacity, inadequate information processing and inferior use of metacognitive skills such as planning or monitoring strategies $[53,54]$. Consequently, according to the Model of Coping Modes (MCM), anxious students feel a strong emotional arousal that causes their use of avoidant behaviors in order to defend themselves from aversive emotional events [55].

Nelson and Harwood carried out a meta-analysis on 58 studies aimed at analysing anxious symptoms in students with learning disabilities (LD) [56]. They found that around the $70 \%$ of pupils with LD presented anxious symptoms and they interpreted this evidence on the basis of a common cerebral able to explain the elevated cooccurrence. Up to now, research in this area has identified dyscalculia or mathematics disabilities as the sub-type of learning disabilities more frequently associated to school anxiety [57,58]. Therefore, mathematics anxiety is conceived as an unpleasant emotional reaction to tasks requiring managing numbers or solving problems. These tasks 
Page 3 of 8

are perceived as threatening to self-esteem and reinforce the use of avoidance behaviors by hampering subsequent improvements in curricular skills at long term [59]. This state of discomfort, therefore, can develop from early education levels and, at long term, could increase and become chronic. As a result, math anxiety cause adult students to avoid or drop-out of mathematics classes as well as to choose professional careers not involving math skills $[60,61]$.

Given the literature findings and speculative interpretations, comparisons of ratings of depression, school anxiety, and self-esteem at school endorsed by pupils with learning disabilities, mathematical disabilities and typical school skills were assessed. Hypothesis 1: Pupils with learning disabilities and mathematical disabilities would have higher scores on anxiety and depression at school than pupils with typical learning skills. Hypothesis 2: Pupils with learning disabilities and mathematical disabilities would have lower scores on self-esteem at school than pupils with typical learning skills. Hypothesis 3: Girls would have higher scores on anxiety and depression at school as well as lower scores on self-esteem at school than boys. Hypothesis 4: Correlations of self- rated school anxiety, depression and self-esteem would be showed by all the three groups with different learning profile.

\section{Methods}

\section{Participants}

The participants were 132 Italian children with an average age of 9 years (range $8-10$; $S D=0.41$ ). With regard to sex, there were 52 girls and 80 boys. Children were all attending the fourth grade of two primary school and had specific Learning Disabilities (LD), or specific Mathematical Disabilities (MD), or Typical Learning (TL). The LD group was composed by 33 children aged 9.2 (range $8.1-9.10$; SD = 0.31 ) with typical intelligence, comprehension and decoding reading disabilities and mathematical disabilities. The MD group was composed by 37 children aged 9.1 (range $8.2-10$; SD $=0.37$ ) with only mathematical disabilities such as written and oral computation ability, symbolic arithmetical reasoning ability, computational speed. The TL group was composed by 62 pupils aged 8.11 (range $8-9.9$; $\mathrm{SD}=0.34$ ) with typical level of learning on school areas. All children were selected from a sample of 270 pupils on the basis of their cognitive level, their comprehension and decoding reading abilities, their mathematical abilities, as below described in the procedure paragraph.

Prior to the start of the study, written informed consent was provided by each participant's parents. Moreover, appropriate local ethics committee approval was obtained from the University of Palermo.

\section{Materials}

Raven's Progressive Matrices (2008): The Raven's Progressive Matrices were administered to measure general intelligence. This test is particularly suitable for children with language and reading disabilities because it evaluates the development of logical thinking and seems to limit the influence of cultural and linguistic factors. Given a matrix of geometric shapes, children were required to select the correct missing shape among a set of items. For each item, evaluation was binary, with a score of 1 being attributed to each correct item, and 0 to incorrect items.

Test-retest reliability of the battery was from $r=.90$. in a nonclinical samples.

\section{Reading comprehension abilities}

The Reading Comprehension was given to evaluate the reading comprehension abilities. The test is a story suited to and standardized for the children's school grade, followed by 10 multiple choice questions relating to the characters and events mentioned in the story. Participants were asked to read the story to themselves and choose the correct answer from a list of 3 written alternatives answers, according to their understanding of the story. Pupils employed, on average, 20 minutes to read and respond to the questions. The scoring parameters of the evaluation were 1 point for each correct answer. Average performance was 6 or more correct choices. This test was administered to select students with average reading comprehension abilities. Internal consistency reliability was a coefficient responding a .60 in non-clinical samples [62].

\section{Reading decoding abilities}

The Reading Decoding Test was given to evaluate the reading decoding abilities. This test required the subjects to read a text out loud. The number and kind of errors made were evaluated. Separate scores were calculated for speed and accuracy. With regard to accuracy, a score of 1 was attributed for each long pause, or addition or omission of syllables, words, or lines. A score of 0.5 was attributed for each error of accent shift, hesitation, or self-correction. Average performance is 6 or less errors. With regard to speed, the total score was obtained by calculating the seconds per number of syllables of text read. Average performance was score of 1.83 syllables/seconds or more. This test was administered to identify the participants with reading decoding difficulties. The reliability coefficient of test for accuracy was $\alpha=.75$ in a non-clinical sample of standardization [63].

\section{Mathematical abilities}

The Test for evaluation of calculation abilities - AC-MT was administered to evaluate the mathematical abilities in children with an age from 6 to 11. This test allows to estimate the various aspects of mathematical learning: written and oral computation ability, symbolic arithmetical reasoning ability, computational speed [64].

The test retests reliability of the battery range .50 to .78 in a nonclinical sample of standardization.

\section{SAFA test}

The Self Administrated Psychiatric Scales for Children and Adolescents (SAFA) test was an Italian test realized by Cianchetti and Fancello aimed at assessing mental impairments in children and adolescents with age ranging from 8 to 18 years. Specifically, SAFA was a battery of 6 scales, subdivided in subscales, suitable to be administrated separately. It included scales to evaluate: anxiety (SAFA A), depression (SAFA D), obsessive-compulsive symptoms (SAFA O), somatic symptoms and hypochondria (SAFA S), phobias (SAFA F). Moreover, each scale consisted of two versions: the first was suitable for subjects aged 8-10 and the second was suitable for subjects aged 11-18 years. Each item was scored from 0 to 2 . In our study, SAFA D and SAFA A were administered. The first measured the depressed mood, with 6 items, such as I often feel sad without any reason. The second measured the school anxiety, with 12 items, such as when I go to school I often feel very nervous. Each item was presented on a 3point scale from true to false. 
The test-retest reliability of the battery was from $r=.90$ in a nonclinical sample of standardization.

\section{School self-esteem level}

The subscale "School Self-Esteem" was derived from the Multidimensional Self-Concept Test - TMA aimed at assessing the global self-worth by means of different scales. It includes 6 subscales: Social, Competence, Affect, School, Family and Physical, which contribute to an overall construct of self-concept. Each subscale can be administered and interpreted separately [65]. The administration can be both individual and collective. In particular, for our research, we have chosen the scale to evaluate the school self-esteem.

The "School Self-Esteem" scale consists of 25 items, positive and negative, related to the way pupils feel about themselves in the school domain. Participants were asked to express their level of agreement with statements such as I am proud of my school work or I do not understand much what I read. Each item was presented on a 4-point Likert scale from Absolutely true to Absolutely false. The test-retest reliability of the battery was from $r=.90$ in a non-clinical sample of standardization.

\section{Procedure}

At the beginning of the research, a screening was done on all the fourth graders from two public schools located in quarters of medium socioeconomic level. The screening was carried out over 3 months. Children were tested on a whole battery of reading comprehension and mathematical tests which are commonly used in the assessment of LD in Italy. All children were assessed with the Raven's Progressive Matrices Reading Comprehension and Decoding test and AC-MT test After the screening were selected 132 children subdivided into three groups: group 1 (LD) characterized by typical intelligence, comprehension disabilities, decoding reading disabilities and mathematical disabilities; group 2 (MD) characterized by typical intelligence, typical reading decoding and comprehension, and mathematical disabilities (dyscalculia); group 3 (TL) characterized by typical learning [66-68].

These children were administered with Depressed Mood, School Anxiety and Self-Esteem tests. The order of presentation of the three tests was balanced. The administration modality was collective. All tests were administered in groups inside the classroom and the procedure did not last than 25 minutes.

\section{Data analysis}

This study had four goals. First, to investigate whether pupils with LD (group with reading and mathematical disabilities), or MD (group with specific mathematical disabilities) would present an higher level of depressed mood and school anxiety than pupils with typical learning skills (TL); second, to investigate whether pupils with LD or MD would present a lower level of school self-esteem than pupils with TL; third, to investigate whether girls would have higher scores on depressed mood and school anxiety and lower scores on self-esteem at school than males; fourth, to study to what extent are correlated depressed mood, school anxiety and school self-esteem level.

First three goals were analyzed by the MANOVA, using school profiles and gender as independent variable, whilst the dependent ones were depressed mood, school anxiety and school self-esteem. Analysis of variance was performed to investigate the relationship between the aforementioned variables. Fisher $\mathrm{F}$ was calculated. The fourth goal was analyzed by bivariate correlations for each group. Pearson's correlation test was performed to assess the associations between investigated variables. The level of significance was set at $p<0.05$. The SPSS Software (Version 20 for Windows) was used.

\section{Results}

The Analysis didn't reveal significant interaction between gender and learning profiles for depressed $\operatorname{mood}(\mathrm{F}(2,131)=.784 ; \mathrm{p}=.459)$, for school anxiety $(\mathrm{F}(2,131)=.760 ; \mathrm{p}=.470)$ and for Self-Esteem $(\mathrm{F}(2,131)=1.109 ; \mathrm{p}=.333)$. However, we found significant differences only for learning profiles. Results revealed significant differences for depressed $\operatorname{mood}(\mathrm{F}(2,131)=9.71 ; \mathrm{p}<.001)$, for school anxiety $(\mathrm{F}(2,131)=16.66 ; \mathrm{p}<.001)$ and for Self-Esteem $(\mathrm{F}(2,131)=10.29 ; \mathrm{p}<.001)$ between the three groups. After the application of Bonferroni post hoc test $(\mathrm{p}<.05)$ we observe significant differences between the group with typical learning profile and all the other groups. To be more precise, the $L D$ group $(M=53.03)$ and the $M D$ group $(M=49.87)$ showed a higher level of depressed mood than the TL group $(M=45.19)$. Similarly, with regard to the School Anxiety, the analysis of Bonferroni post hoc test $(\mathrm{p}<.05)$, revealed that the LD group $(\mathrm{M}=59,84)$ and the MD group ( $M=57.37)$ showed an higher level of school anxiety than the TL group $(\mathrm{M}=46.67)$.

Finally, pupils with LD (M=90.68) and pupils with MD (M=93.33) revealed lower level of Self-Esteem than pupils with typical learning $(\mathrm{M}=101.38)$. See table 1 for descriptive statistics.

\begin{tabular}{|l|l|l|l|l|}
\hline & $\begin{array}{l}\text { Typical } \\
\text { Learning }\end{array}$ & $\begin{array}{l}\text { Learning } \\
\text { Disabilities }\end{array}$ & $\begin{array}{l}\text { mathematical } \\
\text { disabilities }\end{array}$ & $\mathbf{r}$ \\
\hline & M (SD) & M (SD) & M (SD) & \\
\hline $\begin{array}{l}\text { Depressed } \\
\text { Mood }\end{array}$ & $45.07(5.56)$ & $53.03(10.07)$ & $49.92(9.44)$ & 0.135 \\
\hline $\begin{array}{l}\text { School } \\
\text { Anxiety }\end{array}$ & $46.68(9.83)$ & $59.82(11.52)$ & $57.43(12.6)$ & 0.21 \\
\hline $\begin{array}{l}\text { Self } \\
\text { Esteem }\end{array}$ & $100.48(9.61)$ & $90.7(12.75)$ & $93.24(12.59)$ & 0.141 \\
\hline
\end{tabular}

Table 1: Descriptive statistics for Depressed Mood, School Anxiety, Self Esteem by Learning Profiles

Regarding the relationship between Depressed Mood, School Anxiety and Self-Esteem, our analysis showed a significant positive correlation between depressed mood and school anxiety in the group with TL.

We found, also, a significant negative correlation between school anxiety and self-esteem in TL and LD groups. There wasn't any significant correlation in MD group. (table 2-4)

\begin{tabular}{|l|l|l|l|l|}
\hline & & $\mathbf{1}$ & $\mathbf{2}$ & $\mathbf{3}$ \\
\hline 1 & Depressed Mood & 1 & & \\
\hline 2 & School Anxiety & $.393^{\star \star}$ & 1 & \\
\hline 3 & Self-Esteem & -.111 & $-.295^{\star \star}$ & 1 \\
\hline
\end{tabular}

Table 2: Correlations between Depressed Mood, School Anxiety and Self-Esteem in group with Typical Learning. Note. ${ }^{*} p<.05 ;{ }^{* *} p<.01$ 


\begin{tabular}{|l|l|l|l|l|}
\hline & & $\mathbf{1}$ & $\mathbf{2}$ & $\mathbf{3}$ \\
\hline 1 & Depressed Mood & 1 & & \\
\hline 2 & School Anxiety & 0.3 & 1 & \\
\hline 3 & Self-Esteem & -.247 & $-.444^{\star \star}$ & 1 \\
\hline
\end{tabular}

Table 3: Correlations between Depressed Mood, School Anxiety and Self-Esteem in group with Learning Disabilities. Note. ${ }^{* *} \mathrm{p}<.01$

\begin{tabular}{|l|l|l|l|l|}
\hline & & $\mathbf{1}$ & $\mathbf{2}$ & $\mathbf{3}$ \\
\hline 1 & Depressed Mood & 1 & & \\
\hline 2 & School Anxiety & 0.28 & 1 & \\
\hline 3 & Self-Esteem & -.030 & -.272 & 1 \\
\hline
\end{tabular}

Table 4: Correlations between Depressed Mood, School Anxiety and Self-Esteem in group with Mathematical Disabilities

\section{Discussion}

We further extended previous studies on childhood depression and school anxiety by examining the relationships between these variables and self-esteem in school-age children with learning disabilities and typical learning skills.

The major goal in the research reported here was to investigate whether different school learning profiles might account for the levels of depression, school anxiety and school self-esteem in nine-year-old children. These learning profiles include Learning Disabilities (reading and mathematical disabilities), Mathematical Disabilities or Typical School Learning. We choose to study in depth these variables because the school is an important test bank in childhood and affects the process of elaborating self-image and self-concept. Frequently, pupils experience unpleasant emotions and a state of distress in response to situations involving school learning tasks when these are perceived as threatening to self-worth. These emotions and affects can become stable and excessive by creating interferences with subsequent school functioning. Moreover, epidemiological research reveal that the most typical sub-type of anxiety during medium childhood is school anxiety as well as depression now days starts earlier $[69,70]$.

First, we found significant differences in the level of depression and school anxiety as a function of learning profiles. Specifically, pupils with LD and MD self-reported more depressive symptoms and higher school anxiety than their peers with typical level of learning. This finding confirms previous research which have generally demonstrated the occurrence of a maladaptive emotional profile since childhood in critical conditions such as learning disabilities. On the whole, learning disabilities enhance the pupil perception of negative self-competence and increase negative effects such as depressed mood, reduced pleasure and interest, irritability, fatigue, weakened concentration. Moreover, failure at school favors the introduction of task-irrelevant thoughts, creates distraction and lower concentration on the task by interfering with the information processing system. All these negative conditions, therefore, reinforce the poor cognitive functioning and the reduced employ of metacognitive strategies by increasing subsequent opportunities of failures. Consequently, this may lead to the creation of a vicious circle, the "Matthew Effect", which is characterized by the mutual encouragement of an emerging negative self-perception and a decrease in opportunities for the acquisition and refinement of school skills, and thereby reinforcing a maladaptive emotional profile as well as underachievement in school subjects. [71,72].

Second, we found significant differences between our three groups in school self-esteem.

Our pupils with LD or MD reported lower scholastic self-esteem than children with typical learning. It corroborates the results previously obtained which highlight the close relationship between self-esteem and school achievement from primary school on low levels of school self-esteem and academic self-concept are commonly associated with learning disabilities. As result, children with dyslexia or reading comprehension disabilities or mathematical disabilities are more likely to use self-defensive strategies than pupils with typical learning abilities because they need to self-protect since childhood in critical conditions As in our previous studies, children with dyslexia tend to employ more self-handicapping strategies than their peers with typical learning or general learning disabilities involving several areas. Students who experience repeated failure, such as those with learning disabilities or more specifically mathematical disabilities, are more likely to have anxious symptoms and to use avoidant behaviors in order to control the threatening performance [4]. It creates a vicious circle; at long-term, avoidant behaviors tend to undermine future performances and increase learning disabilities. When students have negative ability beliefs about their learning abilities and self-handicap, they should reduce time and strategies they dedicate to their study activities and perform worse. In other words, the dominant viewpoint highlights a mutual relationship between these variables: academic abilities directly influence student's self-evaluation whereas self-esteem seems to affect more indirectly the school skills through mediating variables such as the incremental or entity perception of own abilities, the choice of learning or performance goals, the control of the effort spent during task solution. Generally, students high in self-esteem promote and encourage the development of self-regulated learning $[4,53]$.

In contrast to our third hypothesis, there were no significant differences in the depression, school anxiety and school self-esteem as a function of gender. In the attempt to explain these results we raise a developmental issue. More precisely, this absence of differences may be explained by the young age of our participants. Other findings on gender have generally revealed significant differences between girls and males in the rate of anxiety and depression throughout early adolescence. Cole et al. (2009) provide an exhaustive overview of this issue by postulating the mediation of personal variables such as low levels of self-worth, self-efficacy and self-perceived physical attractiveness. Nevertheless, the authors argue that this higher rate of depression is supported by the greater persistence in girls of negative cognitions strongly related to external and situational events. Moreover, studies on the instability of self-esteem across the life span and the age trajectory suggest how self-evaluation increases throughout adolescence and first adulthood. At this age, gender differences are more evident and girls mostly tend to show lower levels of self-esteem [53].

Other findings to emerge from this research were the correlations between the investigated variables. Consistent with the hypotheses, in pupils with typical learning abilities, the level of depression appears to be positively associated to anxiety at school and negatively correlated to school self-esteem. Moreover, in the group of pupils with LD, school anxiety and self-esteem are negatively correlated. An 
explanation for these results could be the regular co-occurrence between anxiety and depression ranging from 0.40 to 0.70 both in clinical and non-clinical samples. This co-morbidity base on a common core of high negative and upset affects but it doesn't exclude specific characteristics such as the arousal and the fear for anxiety as well as the anhedonia for depression.

On the whole, our results may be attributed to the age of participants and need to be interpreted as evidence in favour of a linear increase of risk to develop anxiety and depression symptoms by the age. In other words, the development of negative thoughts and worries feelings is not stable but increases over time and depends on cognitive and social advances which enable individuals to achieve logical reasoning and elaborate decisional processes. When these conditions are sustained by low self-worth and self-confidence, they create conditions favorable to foster emotional disorders [53].

To sum up, it is crucial to acknowledge that future research is needed building on the shortcoming of this study. The main goal is to provide a richer and more complete understanding of the direction of the relationship between school learning outcomes and emotional disorders in school-aged population.

\section{Implications}

The findings of this study, while preliminary, suggest some interesting implications on the educational and clinical fields concerning prevention as well as treatment interventions.

First, it's hoped to implement prevention programs aimed at identifying at an early age high-risk children showing increased levels of depression and anxiety. These programs would result in positive significant effects to reduce anxious or depressive behaviors as well as to prevent mental health problems or personality dysfunctions in adulthood. The school is the ideal context to provide preventive interventions to a large number of children before a disorder occurs in full scale. The goal of the prevention in mental health domain is to identify sub threshold levels of depression and anxiety in order to reduce the impact of risk factors and reinforce the power of protective factors. One of the most appraised preventive programs is the FRIENDS for Life program. It's a brief cognitive-behavioral program intervention delivered by classroom teachers. It revealed to be effective in reducing both anxiety and depressive symptom.

Nevertheless, these programs appear to be economically effective because they reduce societal costs of later interventions which are estimated amount up to Euro 2.700 per year per family.

Second, given the co-occurrence of early emotional disorders and learning disabilities, it might be worth looking further into the possibility to plan multifaceted intervention programs that take account both the specificity of deficits and factors related to the emotional profile. Specifically, these programs train coping and problem-solving strategies to face controllable and uncontrollable problems and reduce the risk of high anxiety by favoring the adaptive management of stressful situations such as school tasks. Consequently, they encourage the development of self-regulated learning strategies and increase the students' perception about their abilities at school. Domain-specific trainings alone are not enough to improve reading or mathematics achievement. In fact, whereas the decoding, comprehension or math treatment gains more progress in single areas, an integrated program should provide more effective support for the maintenance and generalization of improvements by focusing simultaneously on cognitive and emotional/motivational dimensions $[4,53]$.

Finally, we think it's of worth to cite an interesting study which associates educational and clinical approaches. This study, carried out by Collins, Woolfson and Durkin showed the effectiveness of the CBTbased program delivered by teachers in class. In pupils aged 9- to 10years-old the baseline level of anxiety significantly decreased following a program based on coping and problem-solving strategies. Teachers had been trained by school psychologists. These findings highlight the importance to find which are the most appropriate educational and clinical interventions to reduce cognitive maladaptive strategies in school aged children. All both these factors work together to enhance the maintenance and generalization of gathered improvements.

\section{References}

1. Abela Z, Hankin BL (2008) Handbook of depression in children and adolescence, Guilford Press, New York, USA

2. Ahlen J, Breitholtz E, Barrett PM, Gallegos J (2012) School-based prevention of anxiety and depression: a pilot study in Sweden. Advances in School Mental Health Promotion 5: 246-257.

3. Alesi M, Rappo G, Pepi A (2010) Strategie di autosabotaggio e autostima in bambini con differenti profili di apprendimento. Ricerche di Psicologia 4: 505-519.

4. Alesi M, Rappo G, Pepi A (2012) Self-esteem at school and selfhandicapping in childhood: comparison of groups with learning disabilities. Psychol Rep 111: 952-962.

5. Alexander-Passe N (2006) How dyslexic teenagers cope: an investigation of self-esteem, coping and depression. Dyslexia 12: 256-275.

6. Allison VL, Nativio DG, Mitchell AM, Ren D, Yuhasz J (2014) Identifying symptoms of depression and anxiety in students in the school setting. J Sch Nurs 30: 165-172.

7. Beck AT, Rush AJ, Shaw BF, Emery G (1979) Cognitive therapy of depression. Guilford Press, New York, USA.

8. Bernaras E, Jaureguizar J, Soroa M, Ibabe I, Cuevas C (2011) Child depression in the school context. Procedia - Social and Behavioral Sciences 29: 198-207.

9. Bracken BA (1992) MSCS Multidimensional Self-Concept Scale. PROEd, Austin. Trad It, R. Mazzeo (Ed), TMA Test di Valutazione dell'Autostima. Trento: Erickson.

10. Broeren S, Muris P, Diamantopoulou S, Baker JR (2013) the Course of Childhood Anxiety Symptoms: Developmental Trajectories and ChildRelated Factors in Normal Children. Journal of Abnormal Child Psychology 41: 81-95.

11. Burden R (2008) Is dyslexia necessarily associated with negative feelings of self-worth? A review and implications for future research. Dyslexia 14: 188-196.

12. Burden R, Burdett J (2005) Factors associated with successful learning in pupils with dyslexia: a motivational analysis. British Journal of Special Education, 32: 100-104.

13. Bystritsky A, Khalsa SS, Cameron ME, Schiffman J (2013) Current Diagnosis and Treatment of Anxiety Disorders.Pharmacy and Therapeutics, 38: 41-44, 57.

14. Carroll JM, Iles JE (2006) An assessment of anxiety levels in dyslexic students in higher education. Br J Educ Psychol 76: 651-662.

15. Cianchetti C, Fancello GS (2001) SAFA Scale Psichiatriche di Autosomministrazione per Fanciulli e Adolescenti. Firenze: Organizzazioni Speciali.

16. Cole DA, Jacquez FM, Truss AE, Pineda AQ, Weitlauf AS, et al. (2009) Gender differences in the longitudinal structure of cognitive diatheses for depression in children and adolescents. J Clin Psychol 65: 1312-1326.

17. Collins S, Woolfson ML, Durkin K (2013) Effects on coping skills and anxiety of a universal school-based mental health intervention delivered in Scottish primary schools. School Psychology International 1: 16. 
18. Cornoldi C, Colpo G (2001) Prove oggettive MT di lettura, Firenze: Organizzazioni Speciali.

19. Cornoldi C, Lucangeli D, Bellina M (2002) AC.MT Test di Valutazione delle abilità di calcolo - Gruppo MT, Trento: Erickson.

20. Corr PJ, Fajkowska M (2011) Introduction to special issue on anxiety. Personality and Individual Differences 50: 885-888.

21. Jane Costello E, Erkanli A, Angold A (2006) Is there an epidemic of child or adolescent depression? J Child Psychol Psychiatry 47: 1263-1271.

22. Cuijpers P, van Straten A, Smits N, Smit F (2006) Screening and early psychological intervention for depression in schools : systematic review and meta-analysis. Eur Child Adolesc Psychiatry 15: 300-307.

23. Devine A, Fawcett K, Szucs D, Dowker A (2012) Gender differences in mathematics anxiety and the relation to mathematics performance while controlling for test anxiety. Behavioral and Brain Functions 8: 33-41.

24. Eberhart NK, Shih JH, Hammen CL, Brennan PA (2006) Understanding the sex difference in vulnerability to adolescent depression: An examination of child and parent characteristics. Journal of Abnormal Child Psychology 34: 495-508.

25. Egger HL, Angold A (2006) Common emotional and behavioral disorders in preschool children: presentation, nosology, and epidemiology. J Child Psychol Psychiatry 47: 313-337.

26. Emck C, Bosscher R, Beek P, Doreleijers T (2009) Gross motor performance and self-perceived motor competence in children with emotional, behavioural, and pervasive developmental disorders: a review. Developmental Medicine and Child Neurology, 51: 501-517.

27. Faria L, Pepi A, Alesi M (2006) Personal conceptions of intelligence: cross-cultural comparisons between Portuguese and Italian students. Social Behavior and Personality, 34: 815-826.

28. Fergusson DM, Woodward LJ (2002) Mental health, educational, and social role outcomes of adolescents with depression. Arch Gen Psychiatry 59: 225-231.

29. Forsterling F, Binser M (2002) Depression, school performance and the veridicality of perceived grades and causal attributions. Personality and Social Psychology Bulletin, 28: 1441-1449

30. Fröjd SA, Nissinen ES, Pelkonen MU, Marttunen MJ, Koivisto AM, et al (2008) Depression and school performance in middle adolescent boys and girls. J Adolesc 31: 485-498.

31. Fuhrmann P, Equit M, Schmidt K, Von Gontard A (2014) Prevalence of depressive symptoms and associated developmental disorders in preschool children: a population-based study. European Child and Adolescence Psychiatry 23: 219-224.

32. Gerea MK, Villabøa MA, Torgersena S, Kendallb PC (2012) Overprotective parenting and child anxiety: The role of co-occurring child behavior problems. Journal of Anxiety Disorders 26: 642- 649 .

33. Grills-Taquechel AE, Fletcher JM, Vaughn SR, Stuebing KK (2012) Anxiety and reading difficulties in early elementary school: evidence for unidirectional or bi-directional relations?. Child Psychiatry Human Development, 43: 35-57.

34. Hankin BL, Oppenheimer C, Jenness J, Barrocas A, Shapero BJ, Goldband J (2009) Developmental Origins of Cognitive Vulnerabilities to Depression: Review of Processes Contributing to Stability and Change Across time. Journal of Clinical Psychology 65: 1327-1338.

35. Herman KC, Lambert SF, Reinke WM, Ialongo NS (2008) Low academic competence in first grade as a risk factor for depressive cognition and symptoms in middle school. Journal of Counselling Psychology, 55: 400-410.

36. Humensky J, Kuwabara SA, Fogel J, Wells C, Goodwin B, et al. (2010) Adolescents with depressive symptoms and their challenges with learning in school. J Sch Nurs 26: 377-392.

37. Huss M (2012) DepressionenimKindes-und Jugendalter.Monatsschr Kinderheilkd 160: 40-46.

38. Jacobson NC, Newman MG2 (2014) Avoidance mediates the relationship between anxiety and depression over a decade later. J Anxiety Disord 28: 437-445.
39. Joormann J, Quinn ME (2014) Cognitive processes and emotion regulation in depression. Depress Anxiety 31: 308-315.

40. Kessler RC, Berglund P, Borges G, Nock M, Wang PS (2005) Trends in suicide ideation, plans, gestures, and attempts in the United States, 1990-1992 to 2001-2003. JAMA 293: 2487-2495.

41. Kozina A (2014) Developmental and time-related trends of anxiety from childhood to early adolescence: Two-wave cohort study European Journal of Developmental Psychology 1- 14.

42. Krohne HW, Hock M (2011) Anxiety, coping strategies, and the processing of threatening information: Investigations with cognitiveexperimental paradigms. Personality and Individual Differences 50: 916925

43. Lucangeli D, Scruggs TE (2003) Text Anxiety, Perceived competence and Academic Achievement in Secondary School Students, Advances in Learning and Behavioural Disabilities.

44. Mägi K, Hädkind P, Kikas E (2010) Performance-approach goals, taskavoidant behaviours and conceptual knowledge as predictors of first graders' school performance. Educational Psychology, 30: 89-106.

45. Marsh HW, Martin AJ (2011) Academic self-concept and academic achievement: relations and causal ordering. Br J Educ Psychol 81: 59-77.

46. Muris P (2006) Maladaptive schemas in non-clinical adolescents: relations to perceived parental rearing behaviours, big five personality factors, and psychopathological symptoms, Clinical Psychology and Psychotherapy, 13: 405-413.

47. Muris P, Roelofs J, Rassin E, Franken I, Mayer B (2010) Mediating effects of rumination and worry on the links between neuroticism, anxiety and depression. Personality and Individual Differences 39: 1105-1111.

48. Nelson JM, Harwood H (2011) Learning disabilities and anxiety: a metaanalysis. J Learn Disabil 44: 3-17.

49. Onatsu-Arvilommi T, Nurmi J, Aunola K (2002) The development of achievement strategies and academic skills during the first year of primary school. Learning and Instruction, 12: 509-527.

50. Passolunghi MC, Gregori G (2011) Bambini con difficoltà di apprendimento nel calcolo aritmetico: il ruolo dell'ansia e della memoria di lavoro. Psicologia Clinicadello Sviluppo 15: 175-195.

51. Pepi A, Alesi M, Geraci M (2004) Theories of intelligence in children with reading disabilities: a training proposal. Psychol Rep 95: 949-952.

52. Pepi A, Alesi M, Rappo G (2008) Personal conceptions of intelligence affect outcome in a multimedia reading training program. Percept Mot Skills 107: 963-973.

53. Pepi A, Faria L, Alesi M (2006) Personal conceptions of intelligence, selfesteem, and school achievement in Italian and Portuguese students. Adolescence 41: 615-631.

54. Pereira AIF, Barros L, Mendonça D (2012) Cognitive Errors and Anxiety in School Aged Children. Psicologia: Reflexão e Crítica, 25: 817-823.

55. Piek JP, Barrett NC, Smith LM, Rigoli D, Gasson N (2010) Do motor skills in infancy and early childhood predict anxious and depressive symptomatology at school age? Hum Mov Sci 29: 777-786.

56. Rao U (2013) Biomarkers in pediatric depression. Depress Anxiety 30: 787-791

57. Raven JC (2008) Colured Progressive Matrices, Firenze: Organizzazioni Speciali.

58. Rhodewalt F, Vohs KD (2005) Defensive strategies, motivation and the self In AJ Elliott, CS Dweck (Eds), Handbook of competence and motivation. Guilford, New York, USA

59. Riglin L, Frederickson N, Shelton KH, Rice F (2013) A longitudinal study of psychological functioning and academic attainment at the transition to secondary school. J Adolesc 36: 507-517.

60. Rothon C, Head J, Clark C, Klineberg E, Cattell V, et al. (2009) The impact of psychological distress on the educational achievement of adolescents at the end of compulsory education. Soc Psychiatry Psychiatr Epidemiol 44: 421-427.

61. Roessner V (2014) Research in child and adolescent psychiatry: a multidisciplinary, many-faceted endeavor. Eur Child Adolesc Psychiatry 23: $1-2$. 
Citation: Alesi M, Rappo G, Pepi A (2014) Depression, Anxiety at School and Self-Esteem in Children with Learning Disabilities. J Psychol Abnorm Child 3: 125. doi:10.4172/2329-9525.1000125

Page 8 of 8

62. Rubinsten O, Tannock R (2010) Mathematics anxiety in children with developmental dyscalculia. Behav Brain Funct 6: 46.

63. Shahar G, Henrich G, Winokur A, Blatt S, Kuperminc G, Leadbeater B (2006) Self-criticism and depressive symptomatology interact to predict middle school academic achievement, Journal of Clinical Psychology 62: 147-155.

64. Simon E, Dirksen C, Bögels S, Bodden D (2012) Cost-effectiveness of child-focused and parent-focused interventions in a child anxiety prevention program. J Anxiety Disord 26: 287-296.

65. Snowling MJ, Muter V, Carroll J (2007) Children at family risk of dyslexia: a follow-up in early adolescence. J Child Psychol Psychiatry 48: 609-618.

66. Stanovich KE (1986) "Matthew effects in reading: some consequences of individual differences in the acquisition of literacy", Reading Research Quarterly, 21: 360-407.

67. Steca P, Abela JRZ, Monzani D, Greco A, Hazel NA, Hankin BL (2014) Cognitive Vulnerability to Depressive Symptoms in Children: The
Protective Role of Self-efficacy Beliefs in a Multi-Wave Longitudinal Study, Journal of Abnormal Child Psychology 42: 137-148.

68. Terras MM, Thompson LC, Minnis H (2009) Dyslexia and psycho-social functioning: an exploratory study of the role of self-esteem and understanding. Dyslexia 15: 304-327.

69. Teubert D, Pinquart M (2011) A meta-analytic review on the prevention of symptoms of anxiety in children and adolescents. Journal of Anxiety Disorders 25: 1046- 1059.

70. Wright M, Banerjee R, Hoek W, Rieffe C, Novin S (2010) Depression and social anxiety in children: differential links with coping strategies. J Abnorm Child Psychol 38: 405-419.

71. Zhang L (2009) Anxiety and thinking styles. Personality and Individual Differences. 47: 347-351.

72. Zeidner M (2008) Anxiety revisited: Theory, research, applications. In G. J. Boyle, G. Matthews, D. H. Saklofske (Eds.). Personality theory and assessment. Personality theories and models, SAGE Publication, London, UK. 